\title{
Det forførende medie - om autokommunikation i markedsføringen
}

\author{
Af Lars Thøger Christensen
}

\begin{abstract}
Artiklen presenterer forskellige aspekter af markedskommunikation set som autokommunikation - det vil sige kommunikation om og til afsender selv. Moderne marketing er grundlagt på ideen om, at virksomheder kun overlever i langden, hvis de er opmarksomme på markedets ønsker og behov, og branchen arbejder ud fra en ideel forståelse om responsivitet og dialog med kunder og omverden. Artiklen påpeger imidlertid, at den moderne forbruger - eller modtager - oftest forholder sig blasert eller ligegyldigt til reklamens budskaber, hvorimod både reklamebureauerne og deres kunder er højinvolverede $i$ at omsatte budskaberne til symbolsk vardiskabelse inden for virksomhedernes egne rammer. I et ledelsesperspektiv betyder det for det forste, at visioner og holdninger bliver forlenet med en serlig autoritet og forpligtelse for virksomheden, når disse visioner kommunikeres offentligt gennem et eksternt medie. Intern kommunikation fär simpelthen en storre gennemslagskraft, når den sendes ud af huset, og artiklen viser med en rakke eksempler, hoorledes reklamer kan anspore medarbejderne til korpsänd og hensigtsmassig adferd $i$ 'sandhedens øjeblik' - mødet med kunden.
\end{abstract}

Addressing oneself in texts, speeches, ruminations - this is a fact not only of psychology, but also of the history of culture. (Lotman, 1990, 21).

I dag hævder næsten alle virksomheder og organisationer at være i dialog med deres omgivelser ${ }^{1}$. Uanset om vi taler om producenter af forbrugsgoder som eksempelvis mobiltelefoner, fødevarer og bøger, eller om offentlige institutioner som skoler, børnehaver og sygehuse, hedder det således, at disse organisationer fortløbende kommunikerer med deres omgivelser for bedre at kunne tilpasse sig disses - kundernes, brugernes, interessenternes - ønsker, krav og behov. Med dialogen antages virksomheder og organisationer med andre ord at kunne udvikle og tilpasse sig en verden i stadig forandring. Selv om de færreste af os forventer at blive hørt, når virksomheder og organisationer udvikler deres produkter og serviceydelser, og selv om mange efterhånden har opbygget en blasert attitude overfor begreber som kommunikation og dialog, er forestillingen om den lyttende og markedstilpassende organisation stadig en central dimension af de fleste virksomheders og organisationers selvbillede.
Denne udvikling kan i vid udstrækning tilskrives marketing. I sin moderne form er marketingdisciplinen grundlagt på ideen om, at virksomheder kun vil kunne overleve i længden, hvis deres aktiviteter er funderet $\mathrm{i}$ en omfattende forståelse af markedets ønsker og behov (Kotler, 1991; se også Bouchet, 1991). På tværs af de mange forskellige praksisser, der over tid har formet disciplinen og præget dens omdømme, defineres marketing af dens udøvere som et tovejs kommunikationssystem, hvis fremmeste opgave er at sikre virksomhedens fortsatte sensitivitet og tilpasningsdygtighed i forhold til markedet (Stidsen \& Schutte, 1972). I marketingdisciplinens selvforståelse handler dialog med andre ord om åbenhed og responsivitet over for virksomhedens omgivelser.

Det er nærliggende at affærdige dette organiseringsideal som naivt og fristende at påpege den åbenlyse forskel mellem tovejsretorikken og den envejskommunikation, man stadig udsættes for i størstedelen af dagens markedsføringspraksis. Selv om det lyder smukt, og måske ligefrem demokratisk, at virksomheder og organisationer lytter til deres omgivelser og løbende tilpasser sig 
ændringer i ønsker og behov, forekommer det, fra et lægmandsperspektiv, at kommunikationsmodellen i praksis er simplere, at marketing snarere end dialog handler om kontrol og forførelse. Mens denne kritik, der efterhånden er lige så velkendt som marketingretorikken, har en del på sig, er den imidlertid selv tilbøjelig til at reducere kommunikation til et envejsanliggende. Samtidig overser den, i sin trang til at udnævne marketing til forførelsesinstitutionen par excellence, forførelsens cirkulære natur. Som Søren Kirkegaard gjorde opmærksom på - og som den franske sociolog Jean Baudrillard senere har understreget - er der en tvetydig dobbelthed i al forførelse: En forfører kan kun forføre, hvis han eller hun på forhånd selv er forført af projektet. Baudrillard siger:

De alt for selvsikre diskurser - heriblandt kærlighedsstrategiens diskurs - skal læses på en anden måde: midt i den "rationelle" strategi er de stadig blot instrumenter for en forførelsesskæbne, som de lige så meget er ofre for som iscenesættere af. Ender forføreren ikke med selv at fare vild i sin strategi som i en lidenskabslabyrint? Opfinder han den ikke for at fare vild i den? Og han, som tror at han er herre over spillet, er han ikke det første offer for strategiens tragiske myte? (Baudrillard, 1985, s. 102f).

Jeg skal i denne artikel argumentere for, at et tilsvarende princip er på spil inden for marketing. Mens den typiske markedsføringspraksis næppe drejer sig om at vedligeholde egentlige dialoger mellem virksomhed og omverden, er det forestillingen om dialog - forestillingen om den forpligtende forbundenhed med verden - der forlener marketing med sit forførende potentiale. Marketing forfører således ikke direkte via informationsoverførsel fra en 'intern' afsender til en 'ekstern' modtager, men gennem en række aktører, der på forskellig vis forføres af dialogens ide. I det omfang afsender kun kan overbevise eller forføre, hvis denne på forhånd selv er forført, installeres en cirkularitet i markedskommunikationsprocessen, der ikke kan begribes med traditionelle kommunikationsmodeller. Jeg skal i stedet introducere et autokommunikationsperspektiv, der gør det muligt at vise, såvel teoretisk som via talrige eksempler, at marketing er et autokommunikativt organiseringssystem, der gør det muligt for virk- somheden at benytte 'dialogen' med omverdenen til at bekræfte og vedligeholde sig selv. Denne ide diskuteres på flere niveauer, herunder at virksomheder ofte taler med sig selv gennem deres eksternt rettede kommunikation, og at de i kraft af deres eksternt rettede kommunikation i vid udstrækning skaber deres egne omgivelser.

\section{Autokommunikation: Fra tekst til medie}

Lingvisten og semiotikeren Yuri Lotman (1977, 1990) har vist, at en kommunikator på én gang er afsender og modtager af sine egne budskaber. Enhver kommunikationssituation, hævder Lotman, rummer en autokommunikationsdimension. Uanset om budskabet er en tale, et vision statement, en strategi eller en reklame, og desuagtet at budskabet som udgangspunkt er rettet mod et eksternt publikum, taler det samtidig til afsender selv. Når en poet, eksempelvis, læser sine egne digte på tryk får vedkommende en oplevelse, der har mindre med manuskriptet at gøre end med det forhold, at det nu er oversat til et sæt af tegn med højere status og autoritet i samfundet - det trykte ord (Lotman, 1990).

En tilsvarende oplevelse får enhver, der konfronteres med egne tekster i eksterne medier. Selv om mediet ikke nødvendigvis ændrer teksten æstetisk, forlener det budskabet med en aura af seriøsitet, der forpligter afsender, fordi det herefter er tilgængeligt for andre og, ikke mindst, fordi det nu 'eksisterer' i en offentlig og anerkendt form. Mediet bliver med andre ord budskabet, som McLuhan og Fiore (1967) formulerede det i en lidt anden kontekst. Mens denne erkendelse ligger i logisk forlængelse af Lotmans perspektiv, har han interessant nok ikke udfoldet diskussionen af mediets rolle i autokommunikationen yderligere. Med sine særlige egenskaber åbner mediet imidlertid mulighed for såvel forførelse som selvforførelse. Afsenderen eller forfatteren, der ved, at budskabet efterfølgende vil optræde i et eksternt medie, forføres på forhånd til at tillægge sin tekst en særlig rolle og betydning - afhængig, naturligvis, af det konkrete medies status. I det omfang denne selvforførelse præger fremstillingen af teksten, er der efterfølgende potentiale for en ekstern forførelsesproces.

I autokommunikationen træder det primære budskab, som afsender selv har konstrueret, i 
alle tilfælde i baggrunden til fordel for koden eller omstændighederne omkring budskabet. Lotman pointerer, at en tekst benyttes som kode, når den ikke tilføjer information, men påvirker selvforståelsen hos den, der har skabt den. Vi ser her en parallel til teorier om auto-poiesis og selvreference. Biologerne Humberto Maturana og Francisco Varela (1980) har således vist, at det levende system skaber sig selv ved kontinuerligt at henvise til systemets egen opbygning og logik. Når systemet rækker ud over sine egne grænser, sker dette, ifølge Maturana og Varela, ikke for at indhente ny information, men for at specificere og bekræfte systemets identitet. Systemets kommunikation med dets omverden er således karakteriseret af en grundlæggende cirkularitet, der sikrer systemets selvopretholdelse. Med samme udgangspunkt har sociologen og systemteoretikeren Niklas Luhmann (1990) gjort opmærksom på, at sociale systemer vedligeholder sig selv, ja kun er tilgængelige for deres medlemmer, gennem kommunikation om kommunikation. Den lukkethed, der hermed postuleres, skal imidlertid modificeres, når vi taler om autokommunikation. Mens cirkulariteten er en integreret dimension af autokommunikationsprocessen, er denne ikke en solipsistisk eller uafhængig proces, eftersom den trækker på autoritets- og statuskoder udefra. Ved at kommunikere via omverdenen bekræfter afsender sin identitet eller (ideale) rolle i verden og demonstrerer dermed for sig selv, at han eller hun eksisterer og formår at udtrykke denne eksistens på en socialt sanktioneret måde. Autokommunikationen rummer således en afgørende rituel dimension, der på den ene side handler om mening og identitet og på den anden side åbner op for forførelse og selvforførelse.

\section{Kultur og ledelse som autokommunikation}

Den menneskelige kultur er, ifølge Lotman (1990), et oplagt eksempel på autokommunikation. Som antropologer har vist (f.eks. Geertz, 1973), kommunikerer enhver kultur med sig selv gennem ritualer, der med tilbagevendende styrke minder dens medlemmer om fællesskabets karakter og værdimæssige udgangspunkt. Uanset om ritualet er en hanekamp, et folketingsvalg eller en markedsanalyse, udtrykker og bekræfter ritualet kulturens særlige beskaffenhed. Mens denne proces, som nævnt, kan forekomme lukket, er det vigtigt at understrege, at kulturen finder sin styrke i, hvad Milton Singer (1984) kalder "its outreaching nature", dvs. i dens evne til at projicere sit selvbillede, og ikke mindst finde bekræftelse herpå, i omgivelserne. Selv om visse kulturer er mere orienterede mod koder - og derfor mere lukkede - end andre, må autokommunikation betragtes som en central dimension i enhver menneskelig kulturdannelse.

Dette gælder også for den kulturdannelse, vi finder i organisationer. Mens Lotmans udgangspunkt er sprogvidenskab og semiotik, har hans autokommunikationsperspektiv således stor relevans for vor forståelse af måden, hvorpå virksomheder kommunikerer. Dette påpeges bl.a. af Broms og Gahmberg (1983), der diskuterer, hvorledes strategier og planer rummer væsentlige autokommunikative dimensioner.

A strategic plan is made partly for the element of hope and belief, the element of myth, inherent in it - and element the organization needs badly. (Broms \& Gahmberg, 1983, s. 490).

Strategier og planer fungerer, ifølge Broms og Gahmberg, som ideale selvbilleder, som virksomheden spejler og vurderer sig selv i. Ved at opstille langtidsplaner fortæller virksomhedens beslutningstagere eksempelvis sig selv og hinanden, hvorledes virksomheden burde ud. Med Bergs (1985, s. 281f) ord kan planer og strategier derfor passende beskrives som syntetiserede abstraktioner over virksomhedens foretrukne selvbillede. Selv om mange planer og strategier slår fejl eller aldrig føres ud i livet (Westerlund \& Sjöstrand, 1975), er denne form for kommunikation afgørende for virksomhedens selvopfattelse og funktionsmåde.

Hvad Broms og Gahmbergs diskussion ikke fanger tydeligt nok er, at virksomhedens selvbillede nødvendigvis skal bekræftes og sanktioneres i omgivelserne. I deres forsøg på at anvende autokommunikationsperspektivet $\mathrm{i}$ den organisatoriske kontekst er de tilbøjelige til at fremstille virksomhedens kultur som en lukket dimension, afskåret fra omverdenen. Hermed undervurderer de imidlertid betydningen af det eksterne medie, der, som jeg har argumenteret for, forlener budskabet med autoritet, status og dermed potentiel gennemslagskraft. Virksomheder benytter faktisk ofte omgivelserne, når de taler med sig selv. I overensstemmelse 
med Lotmans perspektiv fornemmer sådanne virksomheder, at selvovertalelsen har størst effekt, hvis den finder sted via et eksternt medie. Denne erkendelse kan forklare, hvorfor den tidligere administrerende direktør for Danske Bank, Knud Sørensen, ofte talte om bankens værdier og mål, når han var på TV, og hvorfor virksomheder som eksempelvis Novo Nordisk, Lego og Bang \& Olufsen ikke nøjes med at kommunikere deres visioner, strategier og værdisæt $\mathrm{i}$ interne fagblade, men vælger at dele disse tanker med deres omverden. På samme måde som nytårsforsætter virker mere forpligtende, når de udtales offentligt, har holdninger, løfter og planer en særlig betydning for virksomheden og dens medarbejdere, når de annonceres professionelt i eksterne medier.

\section{Reklame som autokommunikation og selvforførelse}

Virksomheders autokommunikation er imidlertid ikke begrænset til specifikt ledelsesmæssige situationer. Også reklamen, den eksternt rettede kommunikation par excellence, kan hævdes at tjene autokommunikative formål. Som Barnett (1988) bemærker, er reklame vigtig for udviklingen af virksomhedens kultur:

Advertisements in the mass media, both print and electronic, provide cultural information as an organization communicates to the environment, it reveals its values and style to those outside the organization, as well as, to its members. How it conducts its public relations, announcements, or services and speeches by its officers tell the public what it would be like to be part of the organization. [...] In other words, the external communication feeds back to impact upon its internal culture. (Barnett, 1988, s. 104f).

Gennem reklamen kommunikerer virksomheden ikke blot til omgivelserne, men fortæller samtidig sig selv, hvem den er, hvor den er på vej hen, og hvad dens rolle er eller burde være. Dette autokommunikative formål er på ingen måde sekundært i forhold til reklamens klassiske funktion som salgskanal. Måske tværtimod - som vi skal se i det følgende.

I modsætning til, hvad mange markedsførere forestiller sig, er de færreste forbrugere nemlig interesserede og involverede $\mathrm{i}$ det, virksomhederne siger om sig selv. Mens populære managementbøger om corporate communication postulerer, at forbrugerne i stigende grad køber virksomheden bag produktet (f.eks., Fombrun, 1996; Kunde, 1997), viser forskningen, at mange forbrugere er ligeglade med, hvem der står bag mærkevarerne (Davidson, 1998). Reklamekonsulenten Adam Morgan (1999) hævder sågar, at de fleste mennesker betragter reklamen som "a nuisance business", en kommunikationsform, vi helst vil være foruden. At tale om markedet som et publikum forudsætter, at de lytter - hvilket sjældent er tilfældet:

Communication suggests active listening, but our target doesn't want to be communicated to, isn't waiting for a further message. (Morgan, 1999, s. 22).

Selv om god reklame naturligvis kan gøre en forskel, er opmærksomhed og interesse en indiskutabel mangelvare i en verden mættet med budskaber, der alle gør krav på at blive hørt og taget alvorligt. Forbrugerne synes ganske vist mere kritiske end tidligere, men denne attitude bør ikke forveksles med en egentlig interesse i virksomhedernes budskaber (Christensen \& Cheney, 2000). Som mange reklametests viser, har den typiske forbruger således ikke meget på hjerte, når han eller hun interviewes om konkrete reklamebudskaber. Reklamen bliver, som Shakespeare siger om gøgen i juni, hørt men ikke bemærket. Dette betyder langt fra, at reklamen ikke har indflydelse på salget af varer. Blot er sammenhængen mellem reklame og salg langt mere kompleks end hidtil antaget.

Hvor den traditionelle modtager, forbrugeren, typisk udviser en ligegyldig eller blasert holdning til reklamens budskaber, er afsenderen imidlertid højinvolveret som ingen andre. Dette gælder såvel reklamebureauet som de kunder, der køber dets ydelser. Som kultursociologen Michael Schudson (1993) gør opmærksom på, er de mest ivrige og entusiastiske modtagere af reklamer typisk de mennesker, der laver dem, betaler for dem eller på anden vis er knyttet til den organisation, som reklamerne handler om. Schudson rapporterer således, at kostbare og veludførte reklamer ofte virker mere overbevisende på investorer end 
tabeller og kurver, der angiver virksomhedens finansielle situation. Samtidig giver reklame virksomhedens salgsfolk tillid i 'marken', fordi penge investeret i reklame signalerer, at virksomheden selv tror på sit produkt. Hermed skabes forudsætningerne for en selvopfyldende profeti baseret på autokommunikation. I detailleddet opnås en tilsvarende effekt, når indkøberne ikke tør undlade at føre de mærkevarer, der reklameres mest for, eller når reklamen medfører, at disse varer flyttes frem på hylderne og fremhæves med andre kommunikationsparametre. I det omfang at mærkevalget er styret af det konkrete vareudbud, kan man med Schudson hævde, at reklamen hjælper med at sælge varer uden nødvendigvis at overtale forbrugeren om noget som helst.

Reklamen er, som Schudson gør opmærksom på, først og fremmest et vigtigt signalsystem inden for forretningsverdenen - et signalsystem, der fortæller investorer, konkurrenter, grossister, detailled, medarbejdere og andre involverede publikummer, at virksomheden formår at udtrykke sig på rette måde og derfor er værd at tage alvorligt. Hermed antager reklamen, uanset om den sælger produkter eller ej, karakter af et 'magisk system' (Williams, 1980), der forfører ved at henvise til sin egen autoritet som medie, dvs. til sin egen kode.

Da reklamemediet, trods jævnlig kritik, stadig har en høj status i samfundet, bliver budskaber bragt i dette medie besjælet med en aura, der potentielt virker forpligtende og dermed forførende på den, der afsender budskabet. I dag søger stadig flere virksomheder at udstrække denne selvforførelse til sine menige medarbejdere.

I en reklame bragt i The Economist udtrykker Lufthansa eksempelvis anerkendelse af de kokke, som bager det brød, der serveres om bord: "Another two of our highly-qualified technical officers." I andre reklamer fra Lufthansa er denne anerkendelse kombineret med formaninger. "It's good to know that we always take our responsibilities seriously", siger Lufthansa således i en reklame, der viser en tekniker, som efterser et af Lufthansas fly. I endnu en reklame viser Lufthansa en purser og en stewardesse, der skal til at servere et måltid om bord. Reklamen siger: "There is no room for compromise". Sådanne autokommunikative reklamer er blevet stadig mere almindelige i de senere år, ikke mindst indenfor luftfartsindustrien. Thai Airways benytter således en tilsvarende kommunikationsform til at minde sine ansatte om deres serviceforpligtelse: "We never forget that today's economy class passenger could be tomorrow's first class passenger." Det kan synes logisk, at virksomheder som flyselskaber, med stor kontaktflade til deres kunder, lægger særlig vægt på at motivere deres ansatte til en serviceorienteret adfærd. Som tidligere SAS-direktør, Jan Carlzon, gjorde opmærksom på, er det i mødet med virksomhedens ansatte, at kunderne møder virksomheden. Dette 'sandhedens øjeblik' måtte virksomheden forstå $\mathrm{og}$, så vidt muligt, kontrollere.

Men også andre brancher - banker, kemiske virksomheder og olieproducenter, etc. - kommunikerer til sig selv via reklamemediet. Med et slogan, der efterhånden er blevet en kliché, siger Chemical Bank således "Expect more from us". Noget tilsvarende siger virksomheder som NCG, Esko-Graphics og, tidligere, Statoil. Som kunde har man uden tvivl hørt noget tilsvarende mange gange før og lægger derfor næppe mærke til det vage løfte. Som ansat derimod, har det en særlig betydning, at budskabet er meldt ud til omverdenen - man kan herefter risikere, at der kommer kunder, som rent faktisk forventer noget mere. I samme stil henvender Gulf Oil sig til sine medarbejdere med følgende reklamebudskaber: "You can't tell a customer we're short of No-nox because of a foggy day in the Azores. Gulf people: meeting the challenge" og "It's pretty spooky rowing around inside a supertanker in a rubber boat. Gulf people: meeting the challenge". Den fællesskabsretorik, der benyttes i disse reklamer, har med sin slet skjulte 'pædagogiske' form et klart autokommunikativt sigte. En annonce fra C.W. Obel, der næsten har karakter af jobannonce, udtrykker forpligtelsen mere indirekte. Reklamen viser i fuldt avisformat en tegning af fire næsten ens babyer, hver med sin ballon. Den ene af de fire babyer, der ser gladere ud end de andre, har imidlertid formet sin ballon som en giraf. Teksten lyder: "Mød en af koncernens kommende medarbejdere!". Som underteksten angiver, ønsker C.W. Obel at illustrere, hvad mange andre virksomheder naturligvis sagt før, at virksomhedens fundament er dens ansatte. Når budskabet annonceres i et eksternt medie, forpligter det imidlertid virksomheden i mere fundamental forstand. Mens de færreste kunder kan forventes at interessere sig for sagen, er virksomhedens ledelse uden tvivl klar over, at dens medarbejdere vil forstå at minde den om dens løfte. I samme ånd har Weekendavisen i 
en lang række annoncer, der én for én præsenterer avisens skribenter og vedkommendes speciale, søgt at markedsføre sig som 'Personlighedernes avis'.

Fællesskabsretorikken er en smule mere sofistikeret i en reklame fra Flügger Farver. Reklamen viser i fuldt dagbladsformat 81 personer, alle klædt i T-shirts med hver sin distinkte farve, således at de tilsammen ligner et udsnit af et farvekort. Under hver person er angivet et navn og en adresse. Teksten lyder: "Danmarks mest levende farvekort. Flügger farver. Så handler du samme sted som malermesteren." Mens underteksten angiver den faglige kompetence, der følger med farvekortet, hvis man handler hos Flügger, fortæller reklamen samtidig virksomhedens ansatte, at de tilhører et professionelt fællesskab, hvori alle medlemmer er lige vigtige. Fjerner man en person fra annoncen, fjerner man samtidig en farve fra paletten - en utænkelig tanke for en farvehandler!

På tværs af deres forskelligheder er afsenderne bag disse reklamer alle opmærksomme på det forhold, at intern kommunikation har en større gennemslagskraft, hvis den sendes 'ud af huset'. Ved at præsentere, lovprise eller formane deres ansatte $\mathrm{i}$ et eksternt medie håber virksomhederne bag disse reklamer at stimulere en række effekter i medarbejderstaben - stolthed, korpsånd og måske oven i købet øget motivation og produktivitet - effekter, som kan være sværere at fremkalde gennem traditionelle interne medier, der typisk tillægges en lavere status. For at overbevise skal den slags budskaber naturligvis svare til medarbejdernes oplevelser i dagligdagen. Men det er en anden historie.

\section{Autokommunikation $i$ anden markedskommunikation}

Det er vigtigt at understrege, at ovennævnte konklusioner ikke begrænses til reklamen i snæver forstand, dvs. annoncer og TV-spots. Også brochurer, blade og andet præsentationsmateriale kan være bærer af en autokommunikationsproces. For år tilbage lavede Danavox en elegant brochure, der med smukke nærbilleder præsenterede en række af virksomhedens medarbejdere. Brochuren fortalte på én gang om virksomhedens produkter, høreapparater og om dens medarbejdere, herunder både om deres professionelle virke og deres fritidsinteresser. Om Nikolai Bisgaard, der er vicepræsident for $\mathrm{R} \& \mathrm{D}$ og ansvarlig for udviklingen af nye høreapparater, står der eksempelvis, at han ud over sin beskæftigelse hos Danavox interesserer sig for at lave mad, spille tennis, stå på ski og holde ferie i Frankrig. Tilsvarende står der om Carsten Trads, der er vicepræsident for salg og marketing, at han altid har interesseret sig for lyd, spiller trompet og holder af at slappe af til klassisk musik og jazz. Mens brochuren gjorde det muligt at øge opmærksomheden på virksomhedens produkter, henvendte den sig samtidig til virksomhedens ansatte, der i dette stykke kostbare kommunikation fik mulighed for at udtrykke deres egen identitet samtidig med, at de bekræftede virksomhedens. Mens den omgivende verden næppe tillægger sådanne kommunikationsformer den store betydning, virker de uden tvivl stærkt forpligtende for organisationen selv.

DSB er ude $i$ et tilsvarende ærinde med en række meget personlige personaleportrætter. I jubilæumsudgaven fra 1997 af bladet $U d$ $\&$ Se præsenteredes en række medarbejdere under temaet "Mennesker på banen". Eksempelvis hører vi om Kenn Feldtfos og Henrik Brundt, der er henholdsvis salgsassistent og stationsleder. Mens Kenn holder af britpop og techno, er Henrik til motorcykler og hård rock. Ved at give almindelige medarbejdere stemme og liv i et eksternt medie fortæller DSB sin omverden, at virksomheden, modsat sit rygte, ikke er en bureaukratisk og menneskefjern organisation, men en typisk arbejdsplads med medarbejdere, der ligner alle os andre. Samtidig viser man internt, at man respekterer og værdsætter medarbejdernes personligheder og individualitet. Noget tilsvarende er på spil i $U d$ E̊ Se's majnummer fra 2003, hvor fire indvandrere, der er ansat hos DSB, præsenterer sig selv.

Som kunder er vi næppe dybt involverede i sådanne budskaber. Ansatte, derimod, opfatter ofte de budskaber, som deres arbejdsplads sender ud i verden som en del af sig selv. Hermed forbindes intern og ekstern kommunikation på en potentiel gunstig måde. For en organisation som DSB, der igennem mange år har været udsat for hård kritik, er det altafgørende at bryde med et negativt image - ikke blot i forhold til kunderne, men også for at højne selvfølelsen, moralen og loyaliteten hos en medarbejderstab, der uundgåeligt har været præget af organisationens negative omdømme.

American Airlines har valgt en anden form for autokommunikation. Med bogen $A$ Spirit of 
Greatness har flyselskabet udgivet udvalgte succeshistorier fortalt af virksomhedens egne ansatte. Historierne omhandler typisk daglige interaktioner mellem flypersonale og kunder. En kvinde, der arbejder i lufthavnen ved flyselskabets "First Class check-in" disk fortæller eksempelvis, at hun ofte, når der ikke er passagerer i kø til første klasse, kalder turistklassepassagerer over til sin disk. Den typiske reaktion er: "Frue, jeg rejser ikke på første klasse". Hendes charmerende svar, som virksomheden sikkert er henrykt for, er: "Alle American Airlines passagerer er første klasses; vi har bare ikke så mange sæder oppe foran”. Samtidig med at loyalitet og motivation ofte er en mangelvare blandt ansatte, betragter stadig flere virksomheder deres medarbejdere som omvandrende fragmenter af deres samlede reklameindsats. Visse virksomheder har dog åbenlyst lettere ved at sælge dette perspektiv internt end andre.

Andre medier, der potentielt kan formidle en autokommunikationsproces, er virksomhedsfilosofier, årsberetninger, kunstsamlinger, design, arkitektur, selvbiografier og jobannoncer. Mens Joy (1993) eksempelvis rapporterer, at kunstsamlinger kan skabe stolthed og sammenhold i en medarbejderstab, viser Berg og Kreiner (1990), at virksomheder ofte taler med sig selv via deres egne bygninger. De citerer en marketingchef i en svensk møbelvirksomhed, der forklarer brugen af runde former i virksomhedens hovedkvarter:

The domed roof, in its form and design, consequently symbolizes the rounded details in our assortment. In the interior we have rounded doors and some corners are similarly rounded instead of being right-angled in order to accentuate the identity of the product [...] In the exterior, logo, architecture, and product program we are everywhere confronted with the same round basic form. From the moment we enter the reception we are also confronted with the positive sense of well-being associated with success. No communication problems here. (cited in Berg \& Kreiner, 1990, s. 49).

Som man ser, balancerer denne form for selvforførende autokommunikation imidlertid på grænsen til den lukkede selvoptagethed. Mens autokommunikationen 'sælger' virksomhedens kultur - dvs. dens selvbillede, normer og idealer - til dens egne medlemmer, skal man således være opmærksom på den blindhed, der følger med, hvis man oversælger budskabet.

\section{Autokommunikation som selvoptagethed}

Autokommunikation er et tveægget sværd. Hvor visse virksomheder forstår at forbinde talen til sig selv med en fortsat og konstruktiv interesse for markedet, er mange virksomheder i dag så optaget af deres egen kommunikation, at de glemmer, at denne sjældent har relevans for andre end dem selv. I stedet for, som i de fleste af ovennævnte eksempler, at samtænke kommunikationens interne betydning med dens eksterne funktioner er de fleste virksomheder ganske enkelt optaget af sig selv.

Dette ser vi tydeligst i indforståede reklamer, der overser, at nuancer og detaljer, som er vigtige for virksomheden selv, ikke har den fjerneste interesse for markedet. Om sit navn skriver teleselskabet 3 eksempelvis: "Vi er, trods alt, planet nummer 3 fra solen. I hvert eventyr findes der 3 ønsker. På kinesisk betyder 3 liv. Der var 3 vise mænd. 3 er et lykketal. Du kan kun med sikkerhed vide, hvor du er, hvis du har 3 koordinater. Uden 3 dimensioner findes rummelighed ikke. Uden 3 ingen matematik. 3 er drama, første akt, anden akt, tredje akt." Her kammer selvforførelsen over i selvsving. Selvsving kan ganske vist være yderst nyttig og afføde meget kreative reklamekampagner - se eksempelvis de fortsatte kampagner for Absolut Vodka og Grøn Tuborg eller de subtile reklamer for cigaretmærket Silk Cut, der med deres omfattende brug af intra- og intertekstualitet i udpræget grad taler med sig selv (Christensen, 2001). De færreste virksomheder formår imidlertid at omsætte selvsvinget til budskaber med ekstern betydning.

Mens reklamebranchen selv er berygtet for dens verdensfjerne selvoptagethed, der eksempelvis manifesterer sig ved prisuddelinger for reklamer med begrænset forbrugerrelevans, går mange virksomheder op i enkeltheder, som markedet næppe bemærker. Hos Eccolet Sko har man eksempelvis været overbevist om, at det træsystem af ahorn, som man i mange år har benyttet i virksomhedens forretninger, har betydning for forbrugerne og deres valg af sko. Mens man sagtens kan forstå, at Eccolet ønsker et ensartet look kan man næppe forvente, at forbrugerne interesserer sig for projektet. Ikke desto mindre begrundes 
den slags aspirationer og forfængelighed ofte i markedet. Tilsvarende logik ligger bag utallige virksomheders forsøg på at strømline deres brochurer, reklame og anden kommunikation, så de fremtræder ens på tværs af markeder, der næppe sammenlignes af den typiske forbruger. Når virksomheder taler om deres værdier - der i øvrigt ofte er bemærkelsesværdigt generiske - lukker autokommunikationen sig tilsvarende om sig selv. Mens formuleringen af værdisæt kan være en vigtig brik i en organisationsudvikling, er det ofte en misforståelse, når virksomheder tror, at deres værdier genererer salg og anden ekstern interesse.

Afhængigheden af eksterne medier - og af det 'spejl', som offentligheden repræsenterer - skal således ikke tages som udtryk for, at denne offentlighed som udgangspunkt er involveret i det, virksomheden kommunikerer. Overbevisningen om ekstern interesse er en af de væsentligste misforståelser i vor tids markedsføring. Ikke desto mindre er virksomheden nødsaget til at antage, at en sådan involvering er til stede. Ellers falder selvovertalelsen fra hinanden. Hermed når vi frem til et paradoks: Eftersom autokommunikation virker via eksterne medier, der i kraft af deres status og autoritet bærer selvforførelsen igennem, er afsender nødt til at tage for givet, at omverden har interesse i dens budskaber. Samtidig er det kun ved at erkende, at dette sjældent er tilfældet, at afsender kan bevæge sig ud over autokommunikationens dysfunktionelle dimension, dens selvoptagede og forfængelige lukkethed.

\section{Autokommunikation i markedsanalyse og strategi}

Det forhold, at virksomheden tror, at den kommunikerer med sin omverden, indebærer, at den autokommunikative selvoptagethed rækker længere ind i markedsføringspraksis, end vi har set ovenfor. Mens selvforførelsen er forholdsvis let at få øje på i virksomhedens eksternt rettede budskaber, finder vi den knap så tydeligt udfoldet i aktiviteter som analyse og strategi. Disse aktiviteter, der i endnu højere grad handler om at virkeliggøre forestillingen om åbenhed og dialog, er dog tilsvarende præget autokommunikationens tendentielle selvoptagethed.

Som studier af organisatorisk kommunikation har vist, håndterer virksomheder - på trods af deres udtrykte interesse for omgivelserne - ofte markedsinformation på en måde, der bekræfter velkendte og etablerede perspektiver snarere end at tilføje ny viden. Mere specifikt er det blevet påvist, at organisationer primært indsamler eksterne data for at reducere usikkerhed (Aguilar, 1967; Feldman \& March, 1981), at sådanne data ofte bearbejdes, så de passer til etablerede antagelser og procedurer (Manning, 1986, 1988; Weick, 1979), og at information, som strider mod det velkendte, det praktiske og det billige, typisk afvises som værende irrelevant, inkompatibelt eller utilstrækkeligt underbygget (Ference, 1970; Rogers \& Shoemaker, 1971; Deshpande \& Zaltman, 1982; Fornell \& Westbrook, 1984). Markedsanalyser er derfor ikke nogen garanti for en åben relation til markedet. Som autoritativt medie for virksomhedens selvfølelse skal markedsanalysen imidlertid ikke undervurderes. Feldman and March formulerer det således:

Using information, asking for information, and justifying decisions in terms of information have all come to be significant ways in which we symbolize that the process is legitimate, that we are good decision makers, and that our organizations are well managed. (Feldman \& March, 1981, s. 178).

Markedsanalysen handler med andre ord om selvovertalelse, retfærdiggørelse og legitimitet - og kun i begrænset omfang om markedet (smlg. Meyer \& Rowan, 1977). Selv når analysen udføres af eksterne bureauer, er den ofte organiseret omkring snævre mål af stor vigtighed for virksomheden, men lille relevans for forbrugeren (Schudson, 1993; Fornell, 1976). Sidstnævnte optræder på sin side derfor sjældent $\mathrm{i}$ analysen med andet end forbigående interesse og ofte kun med yderst begrænset indsigt (Alvesson \& Sköldberg, 2000). Alligevel deltager de fleste mennesker pligtskyldigt i de analyser og surveys, de jævnligt udsættes for i vort markedsorienterede samfund (Laufer \& Paradeise, 1990). Da deltagelsen imidlertid er blasert og disinteresseret, er det næppe forbrugeren, som forføres, men virksomheden, der bilder sig ind at være i kontakt med markedet. Sociologerne Romain Laufer og Catherine Paradeise karakteriserer dette forhold som en forførende cirkularitet, hvori forbrugeren blot giver de tegn fra sig, som systemet i forvejen har produceret. 
As a consumer seduced by the images of products in the economic world, the man whose opinion is polled is also a consumer of images in the political sphere, which he regurgitates in form of answers to survey questions. (Laufer \& Catherine, 1990, s. 87-88).

Baudrillard (1984, 1987) radikaliserer denne pointe ved at tilskrive objektet en ironisk strategi, der går ud på at spille spillet og dermed forblive utilgængeligt for det undersøgende subjekt. I alle tilfælde kan man hævde, at markedsanalysen - som medie eller kode betragtet - bliver bærer af en selvforførelsesproces med karakter af selvopfyldende profeti.

Når informationsindsamlingen og -behandlingen er styret og organiseret af en overordnet marketingstrategi, bliver analysens autokommunikative dimension endnu mere udtalt. Hvor den gode marketingstrategi antages at tage udgangspunkt i markedets behov, er det velkendt, at strategien - når denne først er fastlagt - ofte blokerer for alternative ideer og synsmåder og dermed hindrer virksomheden i at opdage ændringer på markedet (Webster, 1988). Selv om dette er i modstrid med traditionelle marketingprincipper, udgør såkaldte 'marketing-orienterede virksomheder' ingen undtagelse til denne praksis. Hvad der fremtræder som en dybtfølt interesse for virksomhedens eksterne verden - for forbrugerpræferencer, holdninger, livsstile - er ofte en afspejling af virksomhedens egne billeder, strategier og aspirationer.

Den proaktive marketingsstrategi virkeliggør for alvor det selvopfyldende profeti ved bevidst at operere 'på forkanten' af markedets behov. Når virksomheder søger at respondere på ønsker og behov, der endnu ikke er artikuleret eller på anden vis ekspliciteret i markedet, bidrager de potentielt til skabelsen af den omverden, de mener at afdække. Dette er eksempelvis tilfældet med 'Det Grå Guld' - en konstruktion, der for længst er itale- og iscenesat af fremtidsforskere, reklamefolk og konsulenter, der gerne vil hjælpe virksomheder med at være på forkant med den udvikling, der forventes. Weick (1979) taler om enactment, når organisationer, i forsøget på at opdage verden, selv 'planter' det, som de efterfølgende opdager. I forlængelse heraf definerer Weick strategier som "organizational ideas that are extended outward, implanted, and rediscovered." (Weick, 1977, s. 290). Man kan følgelig argumentere for, at når virksomheden gennem sin strategiske kommunikation med markedet selv konstruerer det modtagerunivers, som den efterfølgende forventes at tilpasse sig, taler den i vid udstrækning med sig selv. Når denne tale finder sted via et autoritativt medie som en markedsorienteret strategi, kan virksomheden nemt forføre sig selv til at tro, at dens aktiviteter er et nødvendigt og uomgængeligt svar på markedets krav.

\section{Konklusion}

Mens marketingdisciplinen har defineret sig selv som det afgørende forbindelsesled mellem virksomheden og dens marked, synes de dialoger, som marketing organiserer og vedligeholder, primært at forbinde virksomheden med sig selv. Den åbenhed, som postuleres med dialogbegrebet, er således flertydig, idet den rummer elementer af autokommunikation og selvforførelse. Faktisk er det nærliggende at hævde, at marketing - trods disciplinens udtrykte interesse for markedet - bliver en kode, der ikke blot muliggør, men også sanktionerer virksomhedens tendentielle selvoptagethed. Marketing kan, med andre ord, beskrives som et selvforførende medie, der overbeviser virksomheden om dens egen fortsatte orientering mod markedet. Hvorvidt marketing i længden vil kunne opretholde den status og autoritet, der er nødvendig for at facilitere en sådan selvforståelse, er dog stærkt tvivlsomt. I takt med at tilliden til marketing som institution og praksis nedbrydes og erstattes af en voksende ekstern kynisme eller indifference overfor dens budskaber, vil det givetvis blive vanskeligere også at fastholde den interne interesse. Med et stigende behov for identifikation med arbejdsfællesskabet, er det imidlertid ingen overdrivelse at hævde, at reklamens autokommunikative potentiale ofte er større end betydningen som traditionelt massekommunikationsmedie. Forførelsen består i selv at være 'på'.

\section{Litteratur}

Alvesson, M. \& Sköldberg, K. (2000). Reflexive methodology. New vistas for qualitative research. London: Sage.

Barnett, G. A. (1988). Communication and organizational culture. In G. M. Goldhaber \& G. A. Barnett (Eds.), Handbook of organizational communication (101-130). Norwood, NJ: Ablex Publ. Corp.

Baudrillard, J. (1984). "I det tavse flertals skygge". In S. 
Brøgger et al. (Eds.), Implosion og forførelse (30-72). København: Det Kongelige Danske Kunstakademi.

Baudrillard, J. (1985). Forforelse. Århus: Sjakalens Beduinserie.

Baudrillard, J. (1987). Det fatale. Aalborg: Gyldendal.

Berg, P. O. (1985). "Organization change as a symbolic transformation process". In P. Frost et al. (Eds.), Organizational culture (281-299). Beverly Hills: Sage.

Berg, P. O. \& Kreiner, K. (1990). "Corporate archicture: turning physical settings into symbolic resources". In P. Gagliardi (Ed.), Symbols and artifacts: viewes of the corporate landscape (41-67). Berlin: Walter de Gruyter.

Broms, H. \& Gahmberg, H. (1983). "Communication to self in organizations and cultures". Administrative Science Quarterly, 28, 482-495.

Bouchet, D. (1991). "Marketing as a specific form of communication". In H.H. Larsen, D.G. Mick \& C. Alsted (Eds.), Marketing and semiotics. Selected papers from the Copenhagen symposium (31-51). København: Handelshøjskolens Forlag.

Christensen, L. T. (1994). Markedskommunikation som organiseringsmåde. En kulturteoretisk analyse. København: Akademisk Forlag.

Christensen, L. T. (1995). "Når virksomheden taler med sig selv. Auto-kommunikativ ledelse". Ledelse i dag, 20, 32-42

Christensen, L. T. (1997). "Marketing as auto-communication”. In Consumption, markets $\&$ culture, 1, 197-227.

Christensen, L. T. (2001). Reklame i selvsving. København: Samfundslitteratur.

Christensen, L. T. \& Cheney, G. (2000). "Self-absorption and self seduction in the corporate identity game". In M. Schultz, M. J. Hatch \& M. H. Larsen (Eds.), The expressive organization (246-270). Oxford: Oxford University Press.

Davidson, D. K. (1998). "Consumers don't really care about brand products' owners". In Marketing Newe, $32,5-6$.

Fombrun, C. J. (1996). Reputation. Boston: Harvard Business School Press.

Fornell, C. (1976). Consumer input for marketing decisions. A study of corporate departments for consumer affairs. New York: Praeger.

Fornell, C. \& Westbrook, R. A. (1984). "The vicious cycle of consumer complaints". Fournal of Marketing, 48, 68-78.

Geertz, C. (1973). The interpretation of cultures. New York: Basic Books.

Joy, A. (1993). "The modern medicis: corporations as consumers of art". Research in Consumer Behavior, 6, 29-54.

Kotler, P. (1991). Marketing management. Analysis, planning, implementation, and control (7th ed.). Englewood Cliffs, N.J.: Prentice-Hall.

Krippendorff, K. (1984). "An epistemological foundation for communication". Fournal of Communication, 34, 21-36.

Kunde, J. (1997). Corporate religion. Vejen til en sterk virksomhed. København: Børsens Forlag.

Laufer, R. \& Paradeise, C. (1990). Marketing democracy. Public opinion and media formation in democratic societies. New Brunswick: Transaction.
Levy, S.J. (1978). Marketplace behavior - its meaning for management. New York: Amacom.

Lotman, Y. M. (1990). Universe of the mind. A semiotic theory of culture. London: I.B. Tauris.

Lotman, Y. M. (1977). "Two models of communication". In D. P. Lucid (Ed.), Soviet semiotics: an anthology (99101). London: The John Hopkins Univ. Press.

Luhmann, N. (1990). Essays of self-reference. New York: Columbia University Press.

Manning, P. K. (1986). "Signwork". Human Relations, 39, 283-308.

Manning, P. K. (1988). Symbolic communication: signifying calls and the police response. Cambridge, MA: MIT Press.

Maturana, H. R. \& Varela. F. (1980). Autopoiesis and cognition. The realization of the living. Dordrecht, Holland: D. Reidel Publ. Co.

McLuhan, M. \& Fiore, Q. (1967). The medium is the message. London: Allen Lane.

Meyer, J. W. \& Rowan, B. (1977). "Institutional organizations: formal structure as myth and ceremony". American Fournal of Sociology, 83, 340-363.

Morgan, A. (1999). Eating the big fish. How challenger brands can compete against brand leaders. New York: John Wiley $\&$ Sons, Inc.

Rogers, E. M.\& Shoemaker, F. F. (1971). Communication of innovations. A cross cultural approach (2nd ed.). New York: Free Press.

Schudson, M. (1993). Advertising, the uneasy persuasion. Its dubious impact on American society. New York: Basic Books.

Singer, M. (1984). Man's glassy essence. Explorations in semiotic anthropology. Bloomington: Indiana Univ. Press.

Stidsen, B. \& Schutte, T. F. (1972). "Marketing as a communication system: The marketing concept revisited". Journal of Marketing, 36, 22-27.

Webster, F. E. Jr. (1988). "Rediscovering the marketing concept". Business Horizons, 31, 29-39.

Weick, K. E. (1977). "Enactment processes in organizations". In B.M. Staw \& G.R. Salancik (Eds.), New directions in organizational behavior (s. 265-300). Chicago, Ill.: St. Clair.

Weick, K. E. (1979). The social psychology of organizing (2nd ed.). Reading, MA: Addison-Wesley.

Westerlund, G. \& Sjöstrand, S.-E. (1975). Organisationsmyter. Stockholm: Norstedts.

Williams, R. (1980). Problems in materialism and culture. Selected essays. London: Verso.

\section{Noter}

1 De teoretiske overvejelser bag denne artikel findes yderligere uddybet i Christensen $(1994,1997)$ og Christensen \& Cheney (2000).

Lars Thøger Christensen er professor ved Institut for Marketing, Syddansk Universitet. Hans arbejde med denne artikel er støttet af en forskningsbevilling fra Statens Samfundsvidenskabelige Forskningsråd. 